\title{
AllergoOncology: Is ultra-low IgE a potential novel biomarker in cancer? A position paper of the European Academy of Allergy and Clinical Immunology (EAACI)
}

Denisa Ferastraoaru ${ }^{1}$, Heather Bax ${ }^{2}$, Bergmann Christoph ${ }^{3}$, Monique Capron ${ }^{4}$, Mariana Castells $^{5}$, David Dombrowicz ${ }^{6}$, Edda Fiebiger ${ }^{7}$, Hannah Gould ${ }^{8}$, Karin Hartmann ${ }^{9}$, Uta Jappe $^{10}$, Galateja Jordakieva ${ }^{11}$, Debra Josephs ${ }^{2}$, Francesca Levi-Schaffer ${ }^{12}$, Vera Mahler ${ }^{13}$, Aurelie Poli ${ }^{14}$, David Rosenstreich ${ }^{1}$, Franziska Roth-Walter ${ }^{15}$, Mohammed Shamji ${ }^{16}$, Esther Steveling ${ }^{17}$, Michelle Turner ${ }^{18}$, Eva Untersmayr ${ }^{19}$, Sophia Karagiannis ${ }^{20}$, and Erika Jensen-Jarolim ${ }^{15}$

${ }^{1}$ Montefiore Medical Center

${ }^{2}$ King's College London

${ }^{3}$ ENT Research Institute for Clinical Studies

${ }^{4}$ Inserm U995

${ }^{5}$ Brigham and Women's Hospital

${ }^{6}$ U1011 - récepteurs nucléaires, maladies cardiovasculaires et diabète

${ }^{7}$ Children's Hospital Boston

${ }^{8}$ Randall Centre for Cell and Molecular Biophysics,

${ }^{9}$ University of Basel

${ }^{10}$ Research Centre Borstel

${ }^{11}$ Medizinische Universitat Wien

${ }^{12}$ The Hebrew University of Jerusalem

${ }^{13}$ Paul-Ehrlich-Institut

${ }^{14}$ Luxembourg Institute of Health

${ }^{15}$ Messerli Research Institute

${ }^{16}$ Imperial College London

${ }^{17}$ University Hospital Basel

${ }^{18}$ Instituto de Salud Global Barcelona

${ }^{19}$ Center of Physiology, Pathophysiology and Immunology

${ }^{20}$ King's College London

May 28, 2020

\footnotetext{
Abstract

Elevated serum IgE levels are associated with allergic disorders, parasitosis and specific immunologic abnormalities. In addition, epidemiological and mechanistic evidence indicates an association between IgE-mediated immune surveillance and protection from tumour growth. Intriguingly, recent studies reveal a correlation between IgE deficiency and increased malignancy risk. This is the first review focusing on IgE levels and links to pathological conditions, with special focus on the potential clinical significance of ultra-low serum IgE levels and risk of malignancy. In this Position Paper we discuss: a) the utility of measuring
} 
total IgE levels in the management of allergies, parasitosis, and immunodeficiencies, b) factors that may influence serum $\mathrm{IgE}$ levels, c) IgE as a marker of different disorders, and d) the relationship between ultra-low IgE levels and malignancy susceptibility. While elevated serum $\operatorname{IgE}$ is generally associated with allergic/atopic conditions, very low or absent IgE may hamper anti-tumour surveillance, indicating the importance of a balanced IgE-mediated immune function. Ultra-low IgE may prove to be an unexpected biomarker for cancer risk. Nevertheless, given the early stage of investigations conducted mostly in cohort of patients with diseases that influence $\operatorname{IgE}$ levels, in-depth mechanistic studies and stratification of malignancy risk based on associated demographic, immunological and clinical co-factors are warranted.

\section{Hosted file}

main manuscript.docx available at https://authorea.com/users/327434/articles/454999allergooncology-is-ultra-low-ige-a-potential-novel-biomarker-in-cancer-a-position-paperof-the-european-academy-of-allergy-and-clinical-immunology-eaaci

\section{Hosted file}

Figure1.docx available at https://authorea.com/users/327434/articles/454999-allergooncologyis-ultra-low-ige-a-potential-novel-biomarker-in-cancer-a-position-paper-of-the-

european-academy-of-allergy-and-clinical-immunology-eaaci 